18

\title{
Влияние магнитных частиц Со-СоО на свойства электропереноса в однослойном графене
}

\author{
(C) Ю.А. Федотова ${ }^{1}$, А.А. Харченко ${ }^{1}$, А.К. Федотов ${ }^{1}$, М.В. Чичков ${ }^{2}$, М.Д. Малинкович ${ }^{2}$, А.О. Конаков ${ }^{3,4}$, \\ C.A. Воробьева ${ }^{3}$, Ю.В. Касюк ${ }^{1}$, В.Э. Гуменник ${ }^{1}$, M. Kula ${ }^{5}$, M. Mitura-Nowak ${ }^{6}$, \\ A.A. Максименко ${ }^{6}$, J. Przewoźnik ${ }^{7}$, Cz. Kapusta ${ }^{7}$
}

${ }^{1}$ Институт ядерных проблем Белорусского государственного университета,

Минск, Беларусь

${ }^{2}$ Национальный исследовательский технологический университет „МИСиС“,

Москва, Россия

${ }^{3}$ Научно-исследовательский институт физико-химических проблем Белорусского государственного университета, Минск, Беларусь

${ }^{4}$ Московский государственный университет им. М.В. Ломоносова,

Москва, Россия

${ }^{5}$ The Franciszek Górski Institute of Plant Physiology Polish Academy of Sciences,

Krakow, Poland

${ }^{6}$ Institute of Nuclear Physics Polish Academy of Sciences,

Krakow, Poland

${ }^{7}$ AGH University of Science and Technology, Faculty of Physics and Applied Computer Science,

Department of Solid State Physics,

Krakow, Poland

E-mail: XaaTM@mail.ru

Поступила в Редакцию 17 сентября 2019 г.

В окончательной редакции 17 сентября 2019 г.

Принята к публикации 24 сентября 2019 г.

\begin{abstract}
Электрохимическое осаждение кобальта на однослойный CVD-графен приводит к формированию композиционных структур Сo-СoО/графен, что вызывает увеличение электросопротивления и магнетосопротивления. Показано, что магнеторезистивный эффект обусловлен двумя конкурирующими вкладами - отрицательным (ОМР) и положительным (ПМР). ОМР в малых магнитных полях описывается локализационной квантовой поправкой к проводимости Друде в графене. Усиление ПМР в сильных магнитных полях связывается с влиянием лоренцевого механизма в частицах $\mathrm{Co}-\mathrm{CoO}$.
\end{abstract}

Ключевые слова: графен, кобальт, оксид кобальта, электроперенос.

DOI: 10.21883/FTT.2020.02.48885.587

\section{1. Введение}

Создание и исследование магнитных и магниторезистивных композиционных структур на основе графена является весьма актуальной задачей, поскольку открывает перспективы для их последующего применения при создании магнитных туннельных переходов, спиновых вентилей и фильтров, устройств магниторезистивной записи информации и также прочих элементов спинтроники $[1,2,3]$. Подобные композиционные структуры могут успешно синтезироваться посредством осаждения на поверхность графена слоев либо частиц различных ферромагнитных металлов (Co, Ni и т.д.) [2,4]. Следует отметить, что исследование особенностей осаждения и агломерации металлических наночастиц на графене является одной из ключевых проблем его использования в электронных устройствах, поскольку требует решения проблемы формирования низкоомных электрических контактов.

К настоящему моменту опубликовано относительно небольшое количество теоретических и экспери- ментальных исследований магнитных и гальваномагнитных свойств в структурах ферромагнетик/графен, представляющих собой наночастицы либо островки Со на CVD-графене $[1,4,5]$. В данных работах методами фотоэлектронной спектроскопии и магнитометрии показано, что осаждаемые частицы кобальта характеризуются заметным поверхностным окислением и часто имеют структуру типа „ядро Со-оболочка $\mathrm{CoO}^{\circ}$. Тем не менее, электрохимическое осаждение позволяет формировать хороший омический (безбарьерный) электрический контакт, что подтверждается результатами, опубликованными в [5]. Среди механизмов, используемых для описания низкотемпературного электротранспорта и магнитотранспорта в чистом графене, как правило, применяется интерференционный механизм в теории квантовых поправок к проводимости Друде в условиях слабой локализации [6-8]. Другим наиболее часто рассматриваемым механизмом является прыжковый механизм проводимости с переменной длиной прыжка в рамках моделей Мотта [9] и Шкловского-Эфроса в нулевом магнитном поле [10] и моделей Микоши- 
бы [11] и Альтшулера-Аронова-Хмельницкого [6] для электропереноса в ненулевом магнитном поле. В композиционных структурах металл/графен, включающих металлический шунт, нельзя исключать присутствия экстраординарного магниторезистивного эффекта, наблюдаемого при приложении высоких поперечных магнитных полей [12].

В работе [13] показано, что при электрохимическом осаждении металлические наночастицы зарождаются именно в областях с морфологическими изменениями, в том числе, обусловленными остаточными фрагментами $\mathrm{Cu}$ после переноса графена на подложку $\mathrm{Si} / \mathrm{SiO}_{2}$.

Таким образом, полученные ранее результаты свидетельствуют о принципиальной роли состояния границы раздела металл/графен и дефектности исходного графена в комплексе свойств электропереноса и магнитотранспорта в композиционных структурах ферромагнитный металл/графен, в особенности при низких температурах.

Целью настоящей работы является исследование взаимосвязи электрических и магнитных свойств композиционных структур ферромагнитный металл/графен, полученных путем электрохимического осаждения частиц кобальта на однослойный CVD-графен для выявления роли островков кобальта в электропереносе при нулевом и ненулевом внешнем магнитном поле.

\section{2. Методики получения образцов и эксперимента}

Синтез графена производился на установке PlanarTech G2 методом CVD на медной фольге. В качестве прекурсора использовался ацетилен, для разбавления в реактор добавлялся водород в соотношении $\mathrm{C}_{2} \mathrm{H}_{2}: \mathrm{H}_{2}=1: 4$. Температура процесса составляла $1040^{\circ} \mathrm{C}$, давление 6 Torr. Перенос был произведен c использованием пленки полиметилметакриллата (ПММА) в качестве промежуточной подложки. Жидкий полимер (4\% раствор ПММА в анизоле) наносился на медную фольгу с графеном на центрифуге на скорости $1500 \mathrm{rev} / \mathrm{min}$, и запекался в сушильном шкафу при температуре $150^{\circ} \mathrm{C}$. Травление меди производилось в водном растворе хлорида железа (III). Полученная пленка ПММА промывалась дважды в деионизированной воде и укладывалась на подложку. После сушки на центрифуге на скорости $3000 \mathrm{rpm}$, пленка прогревалась на плитке при температуре $120^{\circ} \mathrm{C}$ для устранения складок. Удаление ПММА проводилось в ацетоне.

Электроосаждение частиц кобальта на поверхности графена из электролита, содержащего $\mathrm{CoSO}_{4} \cdot 6 \mathrm{H}_{2} \mathrm{O}$ $(1.25 \mathrm{~g} / \mathrm{L})+\mathrm{NaCl}(0.064 \mathrm{~g} / \mathrm{L})$, осуществлялось на потенциостате ПИ-50-1.1 в комплексе с программатором ПР-8 в реверсивном гальваностатическом режиме при катодной плотности тока $2.5 \mathrm{~mA} / \mathrm{cm}^{2}$ (длительность импульса $5 \mathrm{~s}$ ), анодной плотности тока $1.25 \mathrm{~mA} / \mathrm{cm}^{2}$ (длительность импульса $2 \mathrm{~s}$ ) с общим временем $30 \mathrm{~s}$.

Рамановская спектроскопия выполнена на спектрометре Nicolet Almega XR с помощью рамановского микроскопа, оснащенного программным обеспечением Omnic 8 от Thermo Fisher Scientific USA. Длина волны возбуждающего лазера составляла $532 \mathrm{~nm}$ с использованием уровня мощности лазера около $0.1 \mathrm{~W}$. Диапазон длин волн комбинационного рассеяния изменялся от 400 до $4000 \mathrm{~cm}^{-1}$. Ширина щели спектрографа составляла $2.5 \mu \mathrm{m}$. Рабочее расстояние объектива $\times 100$ микроскопа. Количество сканирований составило 64. Образцы помещали на столик микроскопа и лазерный луч фокусировали на поверхности образца. Количество сканируемых областей по 3 на каждый образец.

Изображения сканирующей электронной микроскопии (СЭМ) получены на микроскопе Vega 3 фирмы Tescan в режиме детектирования вторичных электронов при ускоряющем напряжении $30 \mathrm{kV}$. Атомно-силовая (ACM) и магнито-силовая (МСM) микроскопия выполнены на микроскопе XE-120 (Park System Corporation) в бесконтактном режиме. Использован зонд (кантилевер), игла которого покрыта сплавом $\mathrm{CrCo}$ толщиной $40 \mathrm{~nm}$ и радиусом закругления иглы $<40 \mathrm{~nm}$ (MAGT probes $(\mathrm{AppNano}))$, который был предварительно намагничен вдоль своей вертикальной оси в магнитном поле $B=0.5$ Т. Изображения МСМ получены после исследования топографии поверхности при расположении иглы зонда на высоте $200 \mathrm{~nm}$.

Магнитные характеристики исследованы методом вибрационной магнитометрии в температурном диапазоне $2-300 \mathrm{~K}$ и магнитных полях до 9Т на установке Physical Property Measurement System (Quantum Design).

Температурные и магнитополевые зависимости электросопротивления $R(T, B)$ измерялись четырехзондовым методом на бескриогенной измерительной системе (Cryogenics Ltd) на базе рефрижератора замкнутого цикла в температурном диапазоне $2<T<300 \mathrm{~K}$ и в поперечном магнитном поле с индукцией $B$ до $8 \mathrm{~T}$. При исследовании зависимостей $\rho(T, B)$ and $R_{H}(T, B)$ ток через образец задавался и измерялся с помощью прибора Keithley 6430, который позволял измерять электрическое сопротивление образцов в диапазоне от $100 \mu \Omega$ до $10 \mathrm{G} \Omega$ с точностью не хуже $0.1 \%$. Температуру образцов контролировали термодиодами LakeShore, откалиброванными с точностью $0.0005 \mathrm{~K}$ и имеющими воспроизводимость $0.001 \mathrm{~K}$, что позволило стабилизировать и измерить температуру с помощью контроллера LakeShore 331. Точность измерения удельного сопротивления и постоянной Холла была не хуже $5 \%$, что определялось в основном неточностью измерения геометрических размеров образцов, ширины потенциальных электрических контактов и расстояний между ними.

\section{3. Результаты}

Исследование структуры исходного CVD-графена и графена, на который были осаждены частицы Со 

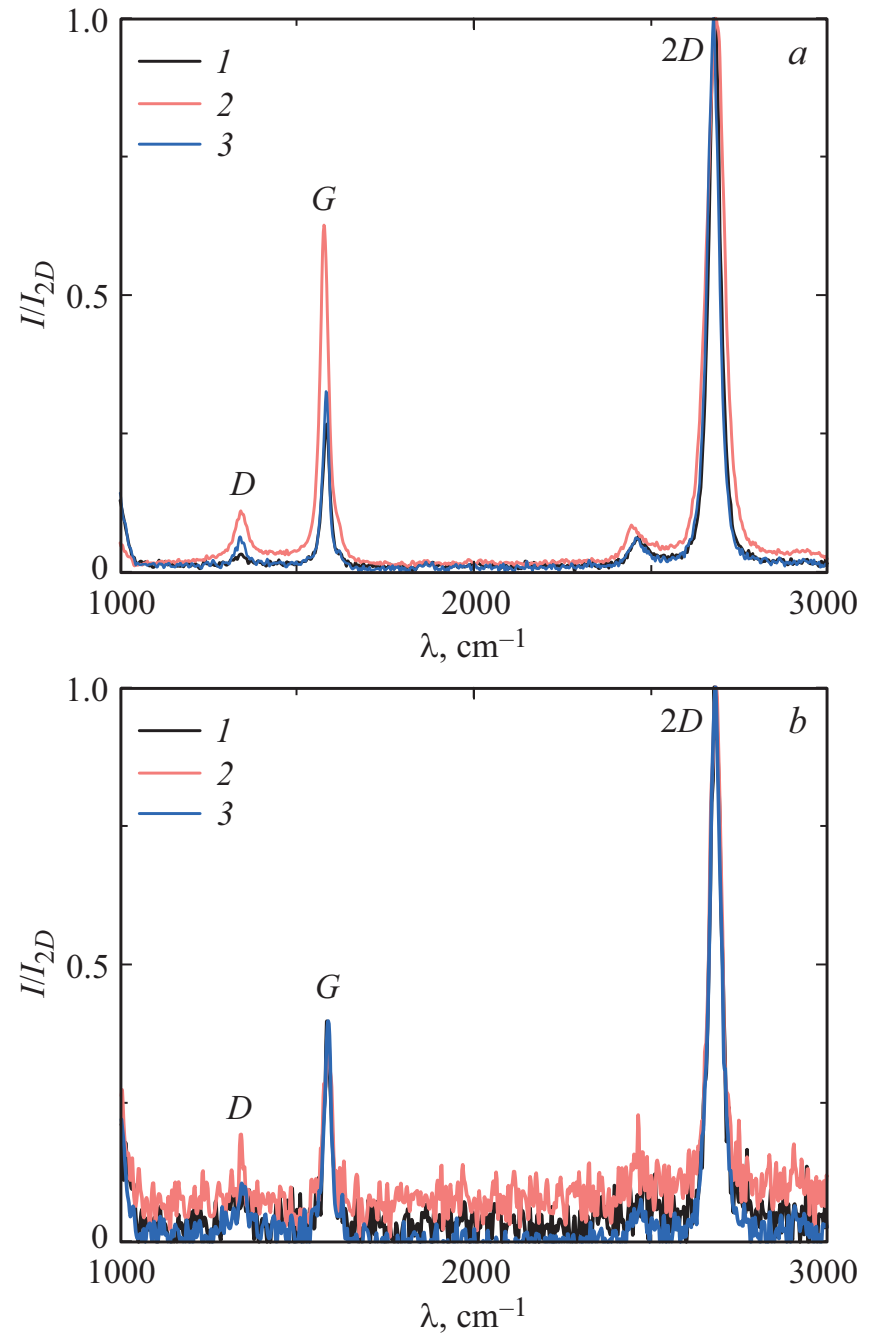

Рис. 1. Рамановские спектры, полученные на образце $\mathrm{Gr} / \mathrm{SiO}_{2}(a)$ и $\mathrm{Co}-\mathrm{Gr} / \mathrm{SiO}_{2}(b)$.

$a$
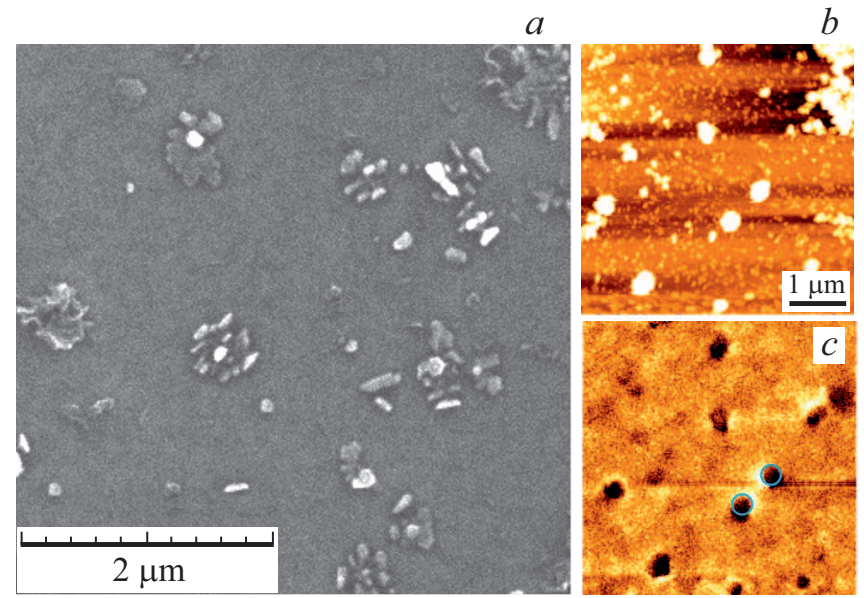

Рис. 2. Морфология поверхности образца $\mathrm{Co}-\mathrm{Gr} / \mathrm{SiO}_{2}$ : $a$ - изображение СЭМ, $b-$ изображение АCM, $c$ - изображение МСМ.
$\left(\mathrm{Co}-\mathrm{Gr} / \mathrm{SiO}_{2}\right)$, проведено методом рамановской спектроскопии, результаты которого показаны на рис. 1.

Образцы $G r / \mathrm{SiO}_{2}$ и $\mathrm{Co}-G r / \mathrm{SiO}_{2}$ в целом демонстрируют поведение, характерное для однослойного графена, что подтверждается рядом методик. Количество слоев графена определялось, как по форме и ширине $2 D$-пика [14], так и по соотношению интенсивностей $2 D$ - и $G$-пиков $[15,16]$. Образцы $G r / \mathrm{SiO}_{2}$ и $\mathrm{Co}-G r / \mathrm{SiO}_{2}$ демонстрируют лоренцевскую линию спектральной полосы $2 D$ и ширину на полувысоте $2 D$-пика $\approx 40 \mathrm{~cm}^{-1}$, что является отличительными признаками монослойного графена [14]. С другой стороны, образцы $\mathrm{Gr} / \mathrm{SiO}_{2}$ и $\mathrm{Co}-\mathrm{Gr} / \mathrm{SiO}_{2}$ в целом демонстрируют поведение, с соотношением интенсивности пиков $I_{2 D} / I_{G}>2$, что также указывает на однослойность графена $[15,16]$. При этом существуют отдельные области образца (рис. 2, a, кривая 2), которые демонстрируют признаки двухслойного графена с отношением интенсивности пиков $I_{2 D} / I_{G}=1.595$ (для двухслойного $2>I_{2 D} / I_{G}>1$ ), а также более широкий $2 D$-пик.

Отношение интенсивности $D$ - и $G$-пиков $\left(I_{D} / I_{G}\right)$ позволяет оценить количество дефектов в графене. Образец $G r / \mathrm{SiO}_{2}$ имеет отношение пиков $I_{D} / I_{G}<0.2$, что, по мнению авторов [17], говорит о неплохом качестве и является обычным для поликристаллических пленок больших размеров. Образец $\mathrm{Co}-G r / \mathrm{SiO}_{2}$ демонстрирует некоторое увеличение $I_{D} / I_{G}$, но остается в рамках неплохого качества.

Дополнительно количество слоев графена проанализировано с помощью соотношения $\omega_{G}=1581.6$ $+11 /\left(1+n^{1.6}\right)$, где $\omega_{G}-$ положение $G$-пика, $n-$ количество слоев [18]. Положение $G$-пика образца $\mathrm{Co}-\mathrm{Gr} / \mathrm{SiO}_{2}$ хорошо согласуется с теорией, дополнительно подтверждая однослойность графена с включением областей двухслойного графена. Однако, в случае образца $G r / \mathrm{SiO}_{2}$ положение $G$-пика уходит в область меньших волновых векторов $\left(1577 \mathrm{~cm}^{-1}\right)$, не попадающих в рабочий диапазон теории, что в работе [19] связывалось с изменением концентрации носителей. Осаждение частиц кобальта вызывает возвращение $G$-пика к значению $1587 \mathrm{~cm}^{-1}$ и увеличивает значение модуля отрицательной слоевой постоянной Холла $R_{h} d$, измеренной при комнатной температуре в магнитном поле $B=1 \mathrm{~T}$, с $126 \mathrm{~m}^{4} / \mathrm{C}$ для образца $\mathrm{Gr} / \mathrm{SiO}_{2}$ до $485 \mathrm{~m}^{4} / \mathrm{C}$ для образца $\mathrm{Co}-\mathrm{Gr} / \mathrm{SiO}_{2}$.

Изображение СЭМ, характеризующее морфологию поверхности образцов $\mathrm{Co}-\mathrm{Gr} / \mathrm{SiO}_{2}$, показано на рис. 2, a. Анализ контраста на изображении СЭМ свидетельствует о том, что осаждение Со происходит преимущественно в виде агломераций (размером до $500 \mathrm{~nm}$ ) из частиц вытянутой формы в сочетании с отдельными осажденными частицами (порядка $50 \mathrm{~nm}$ ). Наблюдаемые области со светлым контрастом могут соответствовать полностью либо частично окисленным частицам, последние из которых могут характеризоваться структурой типа „Со ядро-СоО оболочка“, как доказано в работе [5]. Результаты СЭМ хорошо коррелируют с изображениями 

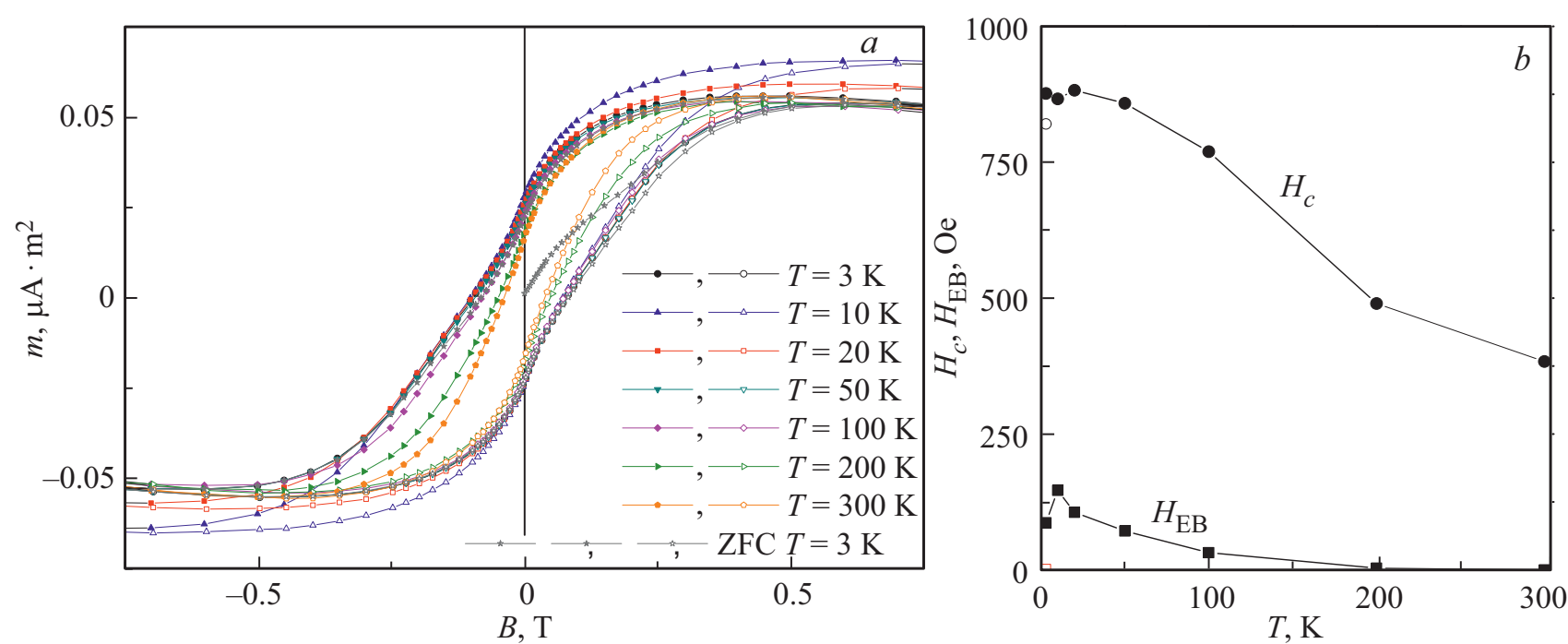

Рис. 3. Кривые намагничивания $m(B)(a)$ и температурные зависимости коэрцитивной силы $\left(H_{c}\right)$ и обменной напряженности магнитного поля $\left(H_{\mathrm{EB}}\right)(b)$ для образца $\mathrm{Co}-G r / \mathrm{SiO}_{2}$.

атомно-силовой микроскопии на рис. 2, $b$. Изображения АCM показывают, что частицы и их агломерации не являются сферическими, поскольку их размер в плоскости примерно на 30-40\% превышает их высоту. На изображениях МСМ (рис. 2,c), наблюдается типичный контраст, полученный при использовании зонда намагниченного перпендикулярно поверхности образца, и свойственный для кобальтовых островковых наноструктур, легкая ось намагничивания которых лежит в плоскости образца [20,21]. В этом случае крупные аггломерации (размером 400-500 nm) осажденных наночастиц отображаются как области со светлым контрастом на одном конце и темным контрастом на другом, что соответствует сильному взаимодействию зонда в областях полюсов наноструктур, магнитные моменты которых лежат в плоскости образца (магнитный дипольный отклик) [22]. Обособленные наночастицы и аггломерации меньшего размера, по всей видимости, являются более магнитомягкими, слабо взаимодействуют с зондом и не демонстрируют заметного магнитного контраста.

Дополнительно магнитное состояние образцов $\mathrm{Co}-\mathrm{Gr} / \mathrm{SiO}_{2}$ исследовано методом магнитометрии. Соответствующие кривые намагниченности, полученные в диапазоне температур 3-300 K, показаны на рис. 3, a. При комнатной температуре $(T=300 \mathrm{~K})$ кривые намагниченности $m(B)$ практически симметричны (относительно $B=0 \mathrm{~T}$ ). Они характеризуются значениями коэрцитивной силы $B_{C} \approx 38 \mathrm{mT}$ и выходом на насыщение при относительно небольших полях $B$ около $0.4 \mathrm{~T}$, что указывает на значительный ферромагнитный вклад неокисленного Со в намагниченность образцов $\mathrm{Co}-\mathrm{Gr} / \mathrm{SiO}_{2}$. При понижении температуры $T<100 \mathrm{~K}$ кривые $m(B)$ становятся асимметричными относительно нулевого поля $B$. Это свидетельствует о наличии обменного смещения, которое при $T=10 \mathrm{~K}$ достигает значений напряженности $H_{\mathrm{EB}}$ до $146 \ni$ (рис. 3,b). Наблюдаемое обменное смещение и достаточно высокие значения коэрцитивной силы $H_{C}$ (до 880 Ое при $T=20 \mathrm{~K}$ ) вероятнее всего обусловлены обменным взаимодействием на границе раздела между Со ядром и оболочкой $\mathrm{CoO}$. Похожие результаты были получены для частиц Co, осажденных электрохимически на твистированный графен [5]. Учитывая, что $H_{\mathrm{EB}}$ обратно пропорционально размеру ферромагнитных частиц [23], относительно небольшие значения $H_{\mathrm{EB}}$, по сравнению, например, с $H_{\mathrm{EB}}=6.5 \mathrm{kOe}$ при $T=10 \mathrm{~K}$ для частиц $\mathrm{Co}-\mathrm{CoO}[24]$ указывают на достаточно большой размер ядер Со в осажденных частицах $\mathrm{Co}-\mathrm{CoO}$.

Наряду с этим, измеренные при $T \leq 100 \mathrm{~K}$ кривые $m(T)$ имеют характерную особенность в виде излома вблизи значений поля $B=0.15$ Т. Подобный вид кривой можно интерпретировать как проявление неоднородности по размерам осажденных частиц, вследствие сложности их структуры типа „ядро-оболочка“. В этом случае ядра неокисленного кобальта перемагничиваются при меньших полях $B$, а точка излома на кривой $m(T)$ соответствует началу перемагничивания областей вблизи оксидной оболочки, проявляющих большую магнитную жесткость вследствие эффекта пиннинга спинов на интерфейсе „ядро-оболочка“. В пользу этого предположения свидетельствует тот факт, что излом на кривых наблюдается при температурах ниже температуры Нееля $T_{\mathrm{N}}$, для $\mathrm{CoO}[25]$.

На рис. 4 представлены температурные зависимости слоевого сопротивления $R_{\square}(T)$ для образцов $\mathrm{Gr} / \mathrm{SiO}_{2}$ (кривая 1) и $\mathrm{Co}-G r / \mathrm{SiO}_{2}$ (кривая 2) в линейном нормированном (рис. $4, a)$ и полулогарифмическом (рис. $4, b$ ) масштабах. Линейность ВАХ на вставке к рис. 4, $b$ указывает на омический характер электрических контактов. Ход кривых 1 и 2 свидетельствует о возрастании 

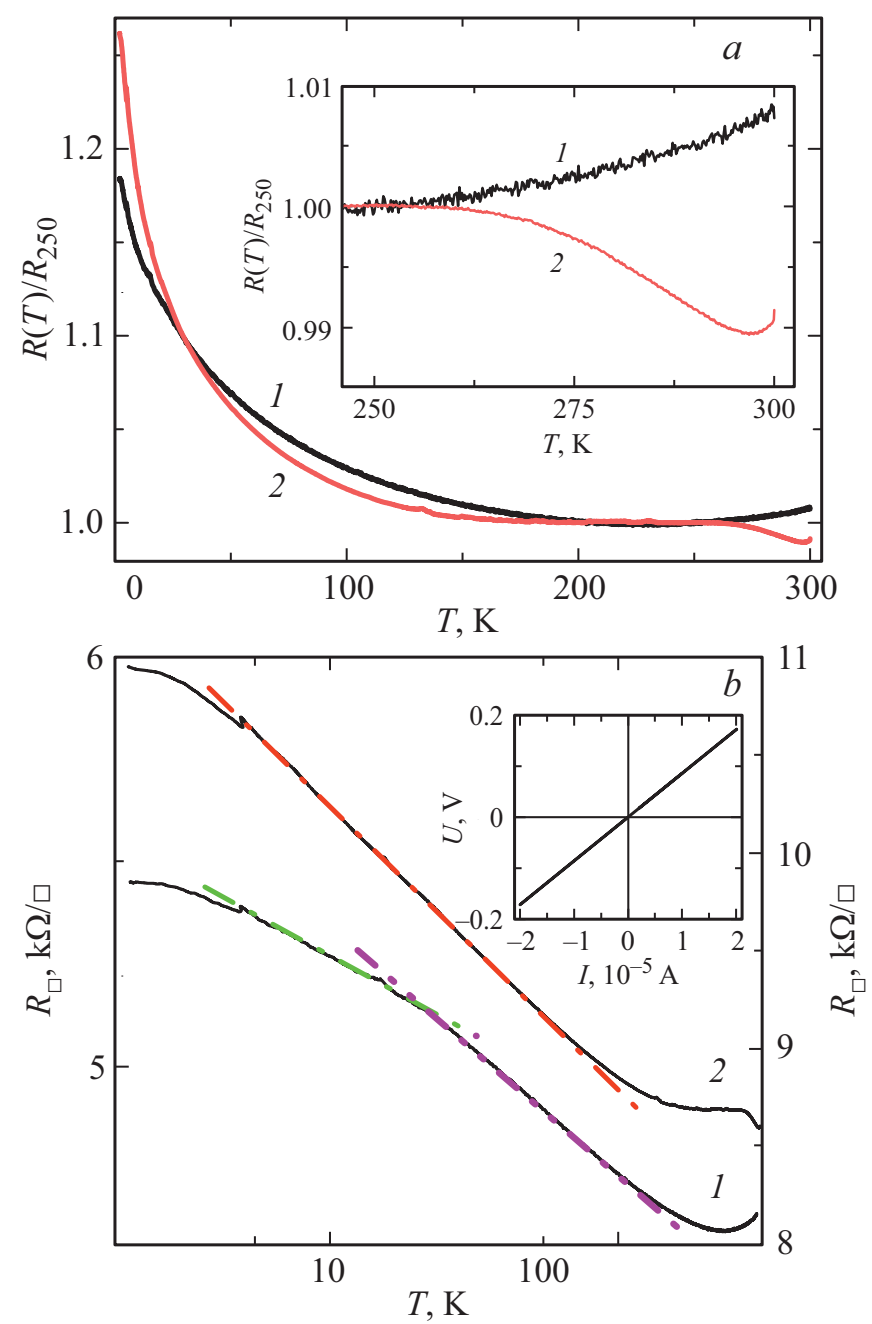

Рис. 4. Температурные зависимости слоевого сопротивления образцов $R_{\square}(T)$ в линейном нормированном $(a)$ и полулогарифмическом (b) масштабах в образцах графена $G r / \mathrm{SiO}_{2}(1)$ и $\mathrm{Co}-G r / \mathrm{SiO}_{2}(2)$. На вставке к рис. 4, $а$ показана область $R_{\square}(T)$ в диапазоне $240-300 \mathrm{~K}$ в увеличенном масштабе. На вставке к рис. $4, b$ приведена $\mathrm{BAX}$ образца $\mathrm{Co}-G r / \mathrm{SiO}_{2}$ при комнатной температуре.

$R_{\square}$ после осаждения частиц, а также о полупроводниковом характере хода $R_{\square}(T)$ в области температур ниже $150-200$ K. Кроме того, как следует из рис. 4, на кривой 2 в области температур выше $260 \mathrm{~K}$ наблюдается резкий спад сопротивления (вставка к рис. $4, a)$, который может соответствовать фазовому переходу оболочки (либо отдельных частиц) $\mathrm{CoO}$ из антиферромагнитного в парамагнитное состояние выше температуры Нееля [25]. Следует отметить, что присутствие $\mathrm{CoO}$ также может давать вклад в наблюдаемое увеличение электросопротивления $\mathrm{Co}-\mathrm{Gr} / \mathrm{SiO}_{2}$ по сравнению с образцом $\mathrm{Gr} / \mathrm{SiO}_{2}$. Отметим также, что рост температуры (выше $225 \mathrm{~K}$ у $G r / \mathrm{SiO}_{2}$ и выше $290 \mathrm{~K}$ у $\left.\mathrm{Co}-G r / \mathrm{SiO}_{2}\right)$ приводит к смене знака температурного коэффициента электросопротивления с отрицательного на положительный, что указывает на металлическое поведение образцов при высоких температурах.

Важной характеристикой изученных образцов является то, что на зависимостях $R_{\square}(T)$, приведенных на рис. $4, b$ в полулогарифмическом масштабе $R_{\square}(T)-L g T$, можно видеть их линеаризацию (соответствующие участки выделены цветными линиями) с выходом на насыщение при понижении температуры. Обнаружение линейных участков в координатах $R_{\square}(T)-L g T$ обычно приписывают наличию вклада квантовых поправок к проводимости Друде в условиях слабой локализации [6-8,26]. Проведенные ниже оценочные расчеты указывают на то, что сбой фазы электронов, приводящих к упомянутому линейному вкладу, происходит вследствие их упругого рассеяния на фононах [27]. На такую возможность также указывает весьма широкий диапазон существования линейных участков на зависимостях $R_{\square}(T)-\operatorname{Lg} T$ (от 5 до $\left.100 \mathrm{~K}\right)$. Как следует из [28], в графене это не редкость, что его резко отличает от металлов и полупроводников, где эффекты слабой локализации обычно проявляются при температурах не выше $10-15$ K [29]. Данный факт можно связать с особенностями фононного спектра углеродных нанослоев и, в частности, с тем, что температура Дебая $\theta_{\mathrm{D}}$ у графена намного выше, чем у любых других квазидвумерных систем на основе металлов и полупроводников. В соответствии с [30] у графена $\theta_{\mathrm{D}}$ достигает величин $1200-2300 \mathrm{~K}$. В результате даже при температурах порядка $200 \mathrm{~K}$ энергия и плотность возбужденных фононов достаточно низки, что приводит к квазиупругому рассеянию электронов на них [27].

Наблюдаемый на рис. 4, $b$ выход кривых $R_{\square}(T)$ на насыщение может быть обусловлен уменьшением проводимости в слоях графена до ее минимального значения у разупорядоченных металлических систем (к так называемой минимальной металлической проводимости $\sigma_{\min }$ ) при стремлении температуры к абсолютному нулю [27]. Однако может быть и альтернативное объяснение этого насыщения - приближение длины свободного пробега к размерам зерен в графене при понижении температуры [31].

Поскольку беспорядок может нарушать условия слабой локализации и приводить к сильной локализации, создающей условия для существования прыжковой проводимости у графена, мы проверили эту гипотезу на основе процедуры фиттинга кривых $R_{\square}(T)$ в соответствии с известным соотношением

$$
R(T) \approx R_{0}^{D} \exp \left[\left(\frac{T_{0}^{D}}{T}\right)^{\alpha}\right] .
$$

Входящие в эту формулу модельные параметры $\alpha, R_{0}^{D}$ и $T_{0}^{D}$ зависят от механизма прыжковой проводимости с переменной длиной прыжка и размерности $D=1,2,3$ исследуемых образцов, а также вида энергетической зависимости плотности локализованных состояний, по которым осуществляются прыжки. Согласно [9,10,32], 
параметр $\alpha$ может быть равен 0.25 и 0.33 для трехмерной $(3 D)$ и двумерной $(2 D)$ моделей прыжковой проводимости Мотта соответственно, либо 0.5 и 0.33 для $3 D$ и $2 D$ моделей прыжковой проводимости по Шкловскому-Эфросу. Заметим, что для обычной зонной модели параметр $\alpha=1$.

Для выявления возможной роли одного из перечисленных механизмов прыжковой проводимости принято представлять зависимости $R_{\square}(T)$ в так называемых координатах Мотта $\operatorname{Ln}\left(R_{\square}(T)\right)-(1 / T)^{\alpha}$, которые при низких температурах дают линеаризацию моттовских кривых для одного из перечисленных выше значений показателя $\alpha$ в экспоненте соотношения (1). Наклон этих линейных участков в соответствующих координатах Мотта $\operatorname{Ln}\left(R_{\square}(T)\right)-(1 / T)^{\alpha}$ позволяет оценить параметры $R_{0}^{D}$ и $T_{0}^{D}$, которые определяют вероятность прыжков и радиус локализации волновой функции в соответствующих моделях. Зависимости $R_{\square}(T)$, представленные на рис. 5, показали, что ни одна из пе-
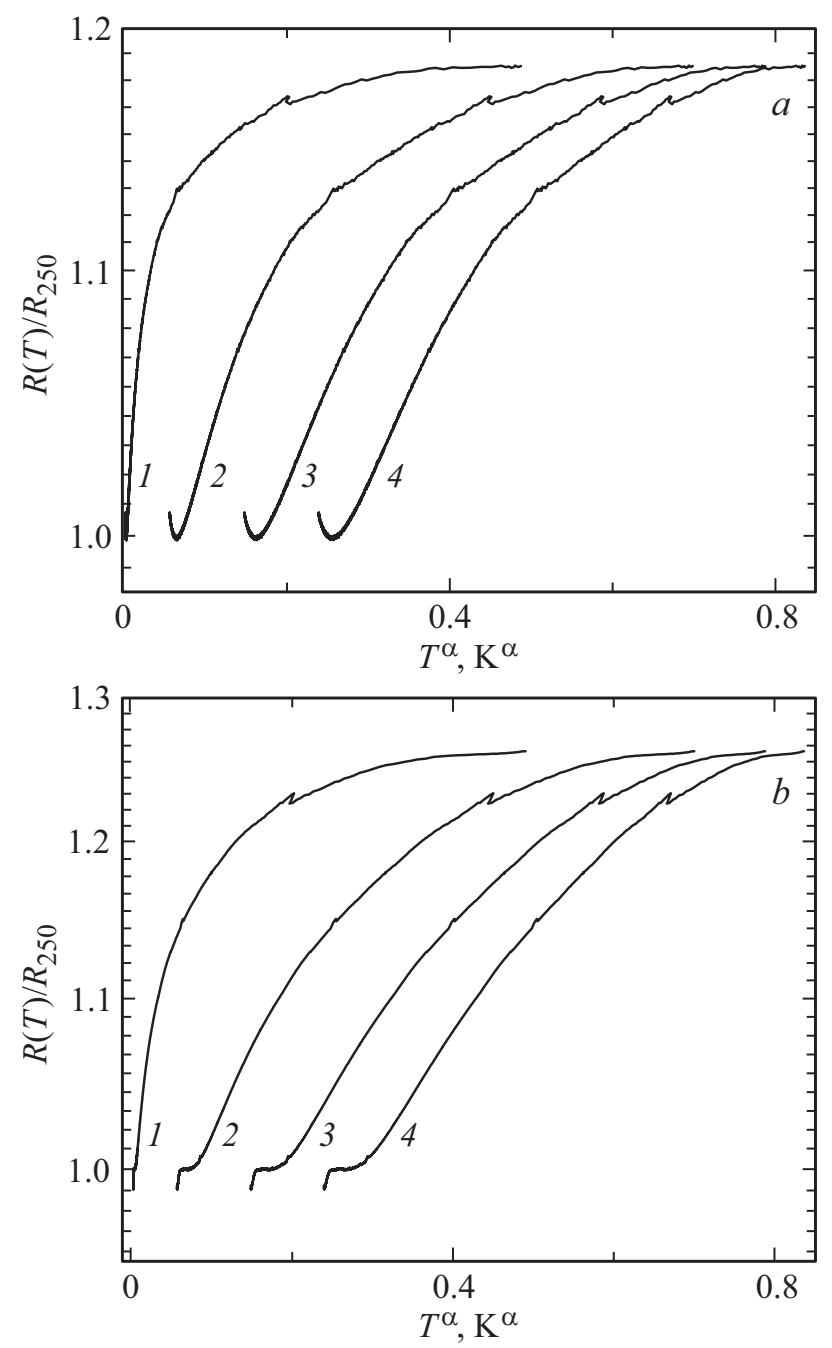

Рис. 5. Температурные зависимости $R_{\square}(T)$ в координатах Мотта $\operatorname{Ln}\left(R_{\square}(T)\right)-(1 / T)^{\alpha}$ для образцов графена $\mathrm{Gr} / \mathrm{SiO}_{2}(a)$ и $\mathrm{Co}-\mathrm{Gr} / \mathrm{SiO}_{2}(b)$ для разных значений экспоненты $\alpha$ в соотношении (1): $1-1,2-1 / 2,3-1 / 3,4-1 / 4$.
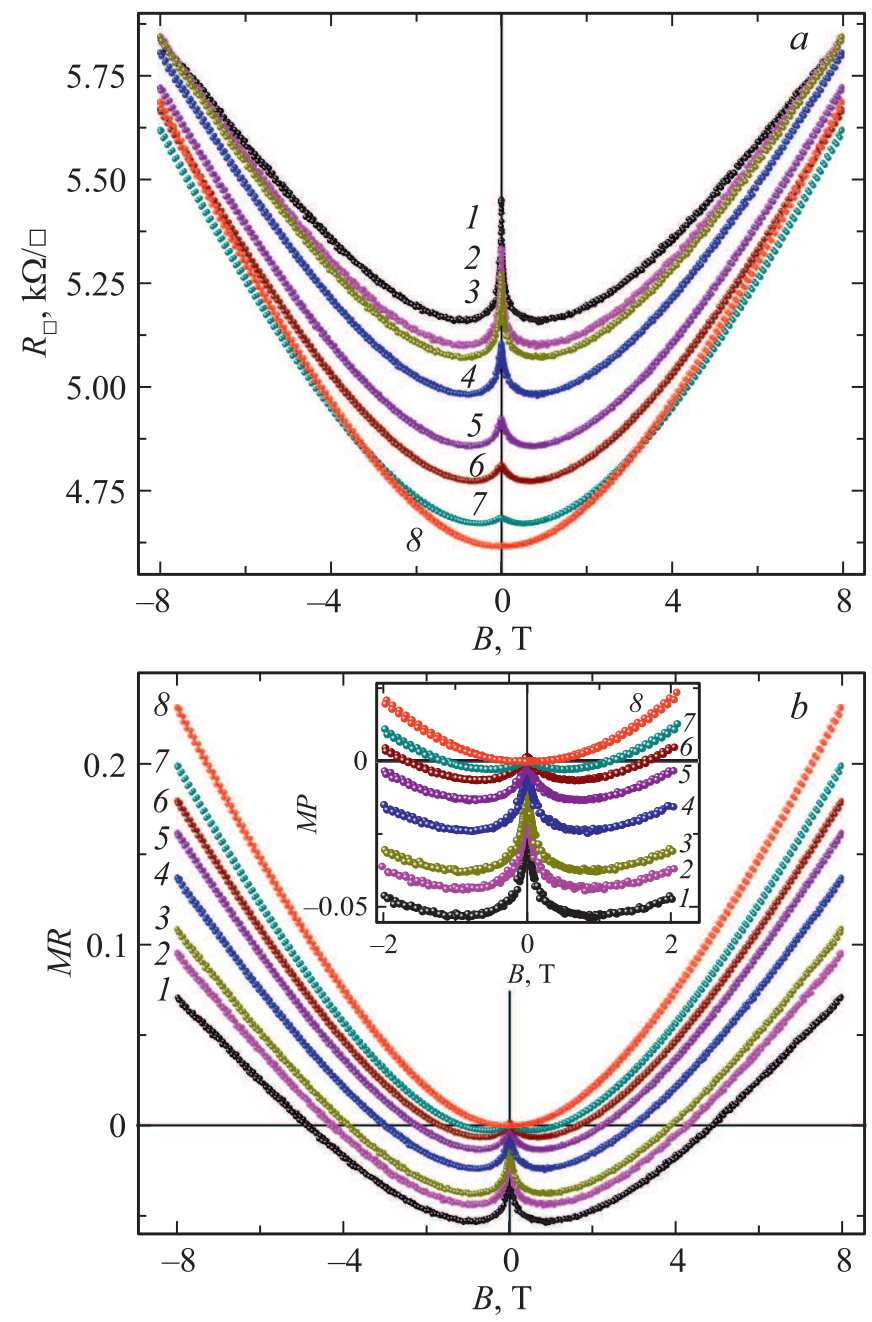

Рис. 6. Зависимости слоевого электросопротивления $R_{\square}(B) \quad(a) \quad$ и $\quad$ относительное магнитосопротивление $M R=\left[R_{\square}(B)-R_{\square}(0)\right] / R_{\square}(0) \quad(b)$ от индукции магнитного поля $B$ в интервале температур $2-300 \mathrm{~K}$ для образца $G r / \mathrm{SiO}_{2}$ : $1-2,2-7,3-10,4-25,5-50,6-75,7-125$, $8-275 \mathrm{~K}$. На вставке к рис. $6, b-$ кривые $M R$ в диапазоне магнитных полей $-2 \leq B \leq 2 \mathrm{~T}$.

речисленных выше моделей не согласуется с экспериментом при низких температурах, поскольку на них нет линейных участков. Это означает, что в изучаемых образцах графена ход $R_{\square}(T)$ при низких температурах в основном определяется теорией квантовых поправок к проводимости Друде.

Для дополнительного подтверждения справедливости этого утверждения проанализируем магнитополевые зависимости слоевого сопротивления $R_{\square}(B)$ и относительного магнитосопротивления $M R(B)=$ $=\left[R_{\square}(B, T)-R_{\square}(0, T)\right] / R_{\square}(0, T)$ в исследованных образцах $G r / \mathrm{SiO}_{2}$ и $\mathrm{Co}-G r / \mathrm{SiO}_{2}$, представленные на рис. 6 и 7 соответственно.

Как следует из рис. 6, исходный графен $\mathrm{Gr} / \mathrm{SiO}_{2}$ характеризуется двумя вкладами в магниторезистивный эффект - отрицательным (ОМР) и положительным 

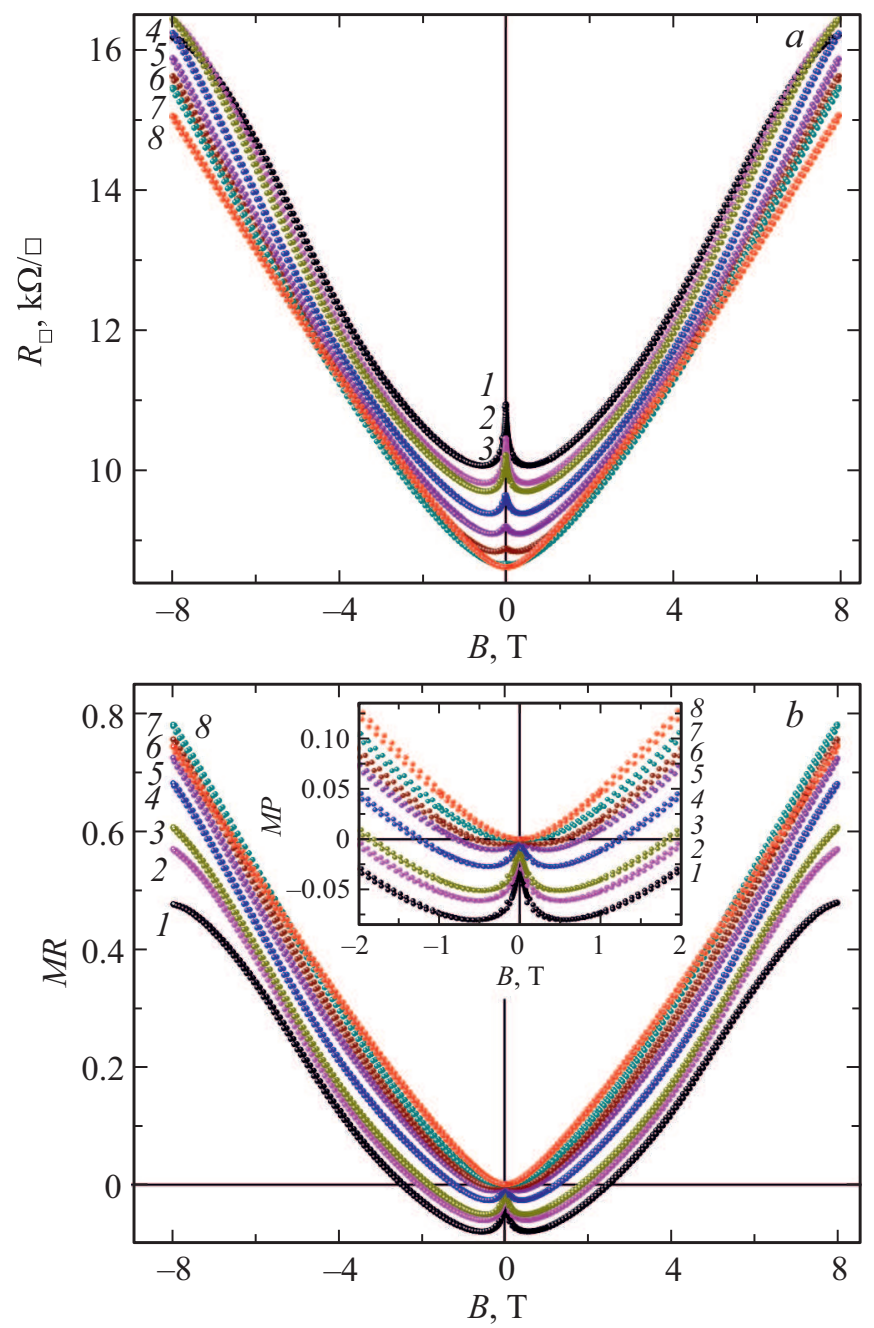

Рис. 7. Зависимости слоевого электросопротивления $R_{\square}(B), R_{\square}(B) \quad(a)$ и относительное магнитосопротивление $M R=\left[R_{\square}(B)-R_{\square}(0)\right] / R_{\square}(0) \quad(b) \quad$ от индукции магнитного поля $B$ в интервале температур $2-300 \mathrm{~K}$ для образца $\mathrm{Co}-\mathrm{Gr} / \mathrm{SiO}_{2}: 1-2,2-7,3-10,4-25,5-50,6-75$, $7-125,8-275 \mathrm{~K}$. На вставке к рис. $7, b-$ кривые $M R$ в диапазоне магнитных полей $-2 \leq B \leq 2 \mathrm{~T}$.

(ПМР). При этом ОМР в $\mathrm{Gr} / \mathrm{SiO}_{2}$ наблюдается лишь в слабых полях (до $0.4-0.8 \mathrm{~T}$ ), но практически во всем исследованном температурном диапазоне (вплоть до $250 \mathrm{~K}$, выше которых имеет место ПМР). При низких температурах $(2-175 \mathrm{~K})$ наблюдается конкуренция этих двух вкладов, так что в магнитных полях с индукцией более $1 \mathrm{~T}$ начинает преобладать ПМР. При этом, зависимости $M R(B)$ в области самых низких температур $(2-5 \mathrm{~K})$ выше $4-5 \mathrm{~T}$ близки к линейным, тогда как в магнитных полях $<4$ Т кривые $M R(B)$ выглядят как квадратичные, что указывает на возможное влияние на электроны силы Лоренца. Кроме того, в полях выше $6 \mathrm{~T}$ для образца $\mathrm{Co}-G r / \mathrm{SiO}_{2}$ при низких температурах $(2-10 \mathrm{~K})$ наблюдаются признаки выхода зависимостей $R_{\square}(B)$ и $M R(B)$ на насыщение (кривые $1-3$ на рис. 7 ).
Как видно из сопоставления рис. 6 и 7, осаждение наночастиц кобальта на графен сужает область существования ОМР как по температуре (ниже $75 \mathrm{~K}$ ), так и по магнитному полю (ниже $0.5 \mathrm{~T}$ ) и усиливает вклад ПМР в полное магнетосопротивление. В образце $\mathrm{Co}-\mathrm{Gr} / \mathrm{SiO}_{2}$ величина $M R$ заметно возрастает, достигая в поле $8 \mathrm{~T}$ (т.е. в области ПМР) $80 \%$, по сравнению с образцом $\mathrm{Gr} / \mathrm{SiO}_{2}$, где она составляла лишь $23 \%$. Это усиление может указывать на то, что ПМР в исследованных образцах может также определяться действием на электроны силы Лоренца в Со ядре. Это означает, что оболочка $\mathrm{CoO}$ не является сплошной, а имеет „проколь“, где есть прямой электрический контакт Со с графеном.

Для демонстрации влияния магнитного поля на смену типа магниторезистивного эффекта (с ОМР на ПМР) и роли осаждения окисленных частиц кобальта на нее, на рис. 8 представлены температурные зависимости $M R(T)$ при разных значениях $B$. Как видно из рис. $8, a$, в образце $\mathrm{Gr} / \mathrm{SiO}_{2}$ в области низких температур, где преобладает
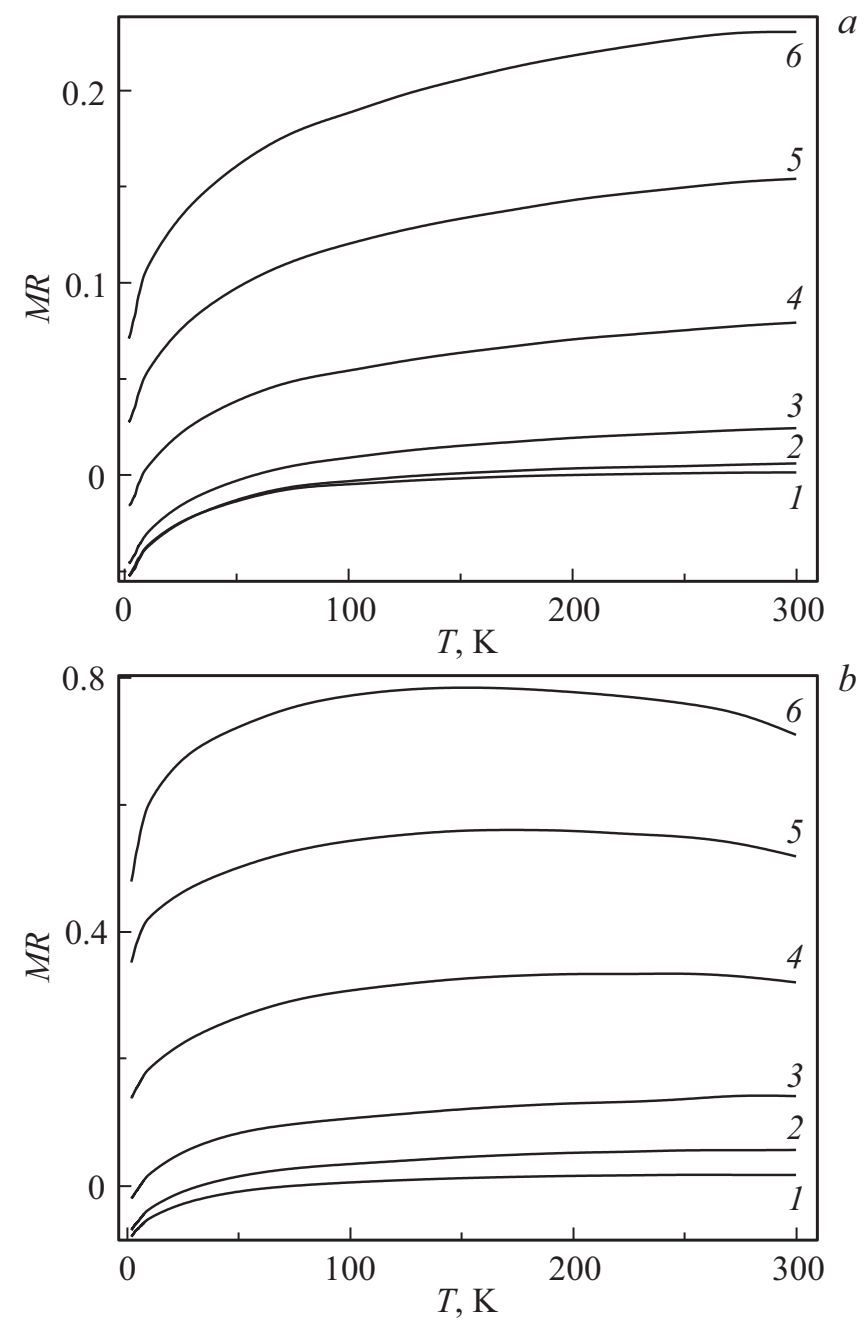

Рис. 8. Температурные зависимости относительного магнитосопротивления $M R(T)$ для образцов $\quad G r / \mathrm{SiO}_{2} \quad(a)$ и $\mathrm{Co}-G r / \mathrm{SiO}_{2}(b)$ в магнитных полях $B: 1-0.5,2-1,3-2$, $4-4,5-6,6-8 \mathrm{~T}$. 
OMP, $M R(T)$ сначала растет, а затем переходит к насышению (кривые 1 и 2 на рис. 8,a). Переход к ПМР с ростом температуры усиливает рост $M R$ как с увеличением температуры, так и магнитного поля (кривые 3-6 на рис. 8,a), также достигая насыщения при комнатных температурах. В то же время, как видно из рис. $8, b$, осаждение окисленных частиц кобальта на графен увеличивает значения $M R$ при всех температурах и существенно изменяет вид зависимостей $M R(T)$. Если при малых значениях $B$ эти кривые по прежнему сохраняют тенденцию к насыщению, то в полях с индукцией $B>3$ Т они проходят через максимумы, положение которых сдвигается в область более низких температур, примерно с $220 \mathrm{~K}$ при $B=4 \mathrm{~T}$ до $150 \mathrm{~K}$ при $B=8 \mathrm{~T}$.

Для выявления роли температуры в смене типа магнеторезистивного эффекта с ОМР на ПМР на рис. 9 представлены зависимости величин $M R_{\min }($ кривые 1$)$ и магнитного поля $B_{\min }$ (кривые 2 ) в точках минимума на зависимостях $M R(B)$ на рис. 6 и 7 для обоих образцов. Как видно, значения $M R_{\min }$ и $B_{\min }$ быстро (практически линейно) снижаются по модулю при повышении температуры в области $2-50 \mathrm{~K}$ (кривые 1), достигая нуля выше $50 \mathrm{~K}$, где ОМР практически исчезает и проявляется ПМР. При этом, если, как отмечалось выше, в исходном графене (кривая 1 на рис. 9, $a$ ) эффект ОМР существует практически во всем исследованном интервале температур, то после осаждения частиц кобальта (кривая 1 на рис. 9, $b$ ) эффект ОМР подавляется полностью уже при температурах выше 130-140 К. Кроме того, смена знака $M R$ с отрицательного на положительный в образце $\mathrm{Co}-G r / \mathrm{SiO}_{2}$ происходит в меньших полях (кривая 2 на рис. 9, $b$ ), чем в исходном графене (кривая 2 на рис. 9,a). Как видно, наиболее сильный спад $B_{\min }$ наблюдается при повышении температуры в области $2-5 \mathrm{~K}$, где при охлаждении образцов на кривых $R_{\square}(T)$ на рис. 4 наблюдается выход на насыщение.

Наличие ОМР в области относительно низких магнитных полей обычно связывается с проявлением вкладов от квантовых поправок. Как сообщалось в [8], в графене с высокой подвижностью носителей заряда (например, для отщепленного графена) обычно учитывают следующие виды квантовых поправок: слабая локализация, в том числе с учетом электрон-электронного взаимодействия $[6,7,33,34]$, междолинное рассеяние и нарушение хиральности [34], слабая антилокализация [33,34] и др. Согласно перечисленным работам, данные вклады в зависимости электросопротивления графена от температуры могут быть как положительными, так и отрицательными. Они обычно описываются соотношениями типа [35],

$\Delta \sigma=\frac{e^{2}}{\pi h}\left(F\left(\frac{B}{B_{\varphi}}\right)-F\left(\frac{B}{B_{\varphi}+2 B_{i}}\right)-2 F\left(\frac{B}{B_{\varphi}+B_{*}}\right)\right)$,

где

$$
F(x)=\ln (x)+\psi\left(0.5+x^{-1}\right)
$$
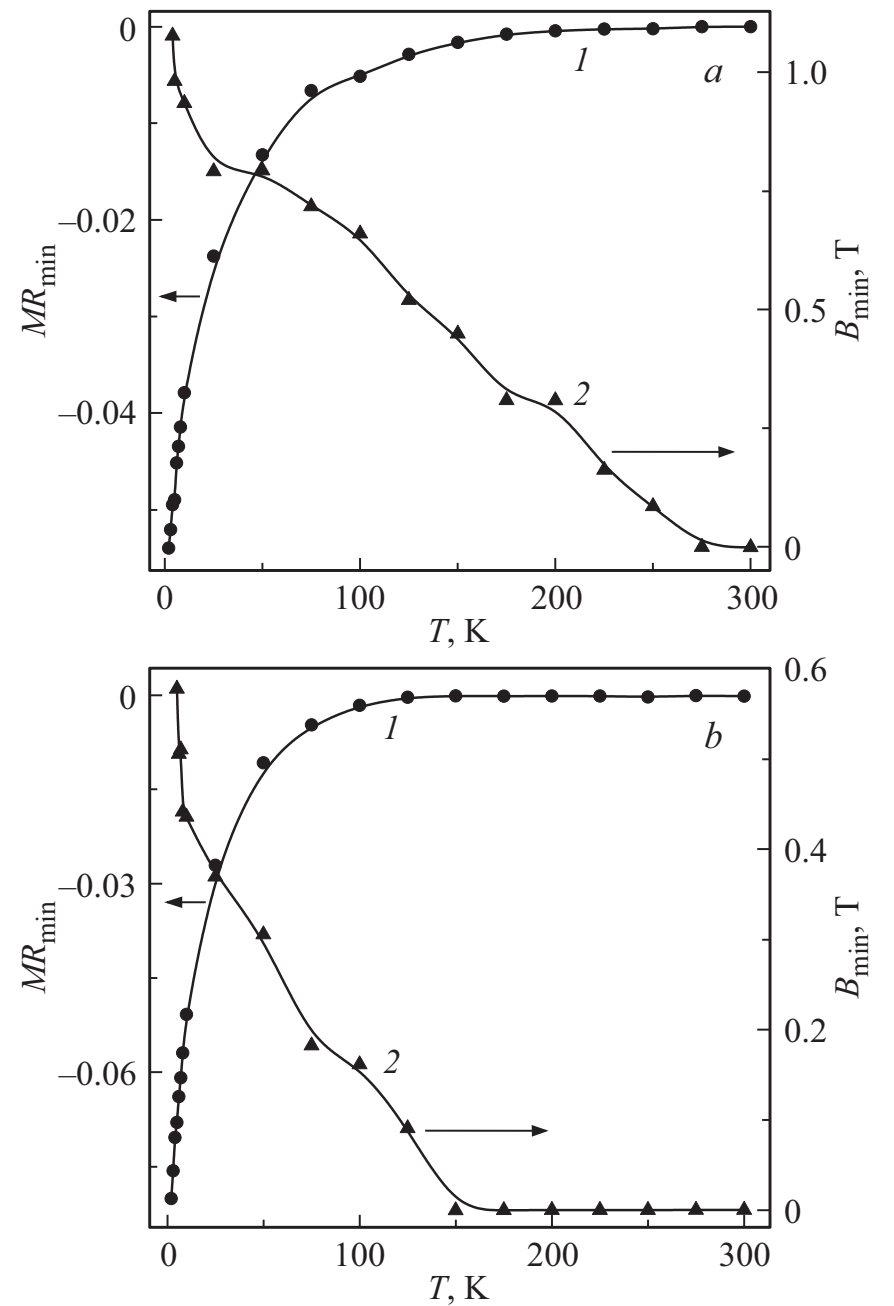

Рис. 9. Температурные зависимости величин $M R_{\min }(1)$ и магнитного поля $B_{\min }(2)$ в точках минимума на кривых $M R(B)$ на рис. 7 и 8 для образцов $G r / \mathrm{SiO}_{2}(a)$ и $\mathrm{Co}-G r / \mathrm{SiO}_{2}(b)$ соответственно.

а характеристические поля определяют времена сбоя фазы носителей заряда для соответствующего процесса. Для вклада от слабой локализации это время равно

$$
\tau_{\varphi}=\frac{4 e D B_{\varphi}}{\hbar}
$$

При этом, согласно теории квантовых поправок [36-38], температурные зависимости времени сбоя фазы $\tau_{\varphi}$ волновых функций электронов имеют степенной вид

$$
\tau_{\varphi}(T) \sim T^{-p},
$$

где параметр $p$ определяется механизмом сбоя фазы волновых функций электронов, теоретические значения которых лежат в диапазоне $1<p<2$ [27].

Соотношение (2) включает поправки от слабой локализации (первый член), а также от слабой локализации с учетом электрон-электронного взаимодействия (второй член и влияние хиральности и коробления (третий 


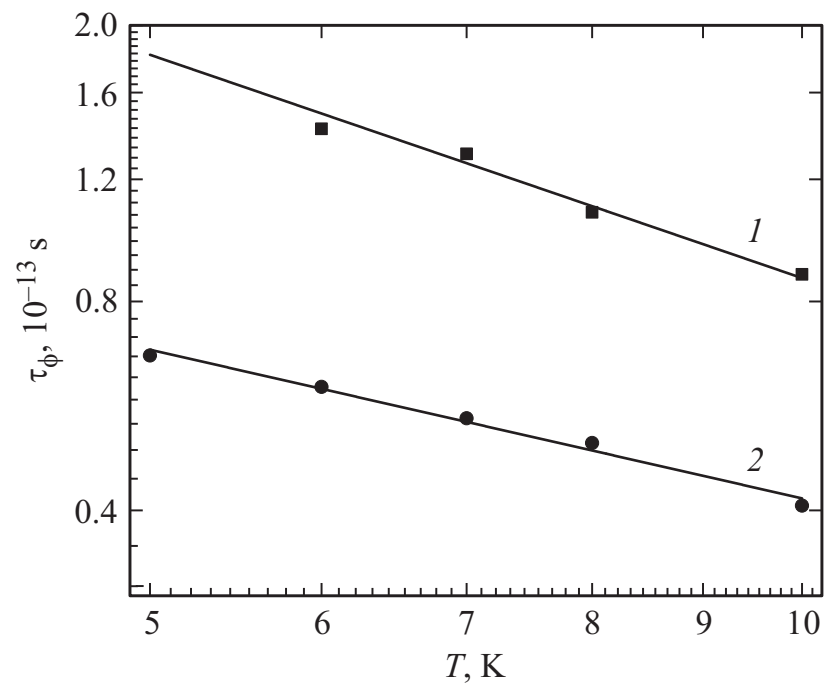

Рис. 10. Температурные зависимости времен сбоя фазы для вклада слабой локализации в квантовые поправки в образцах $\mathrm{Gr} / \mathrm{SiO}_{2}(1)$ и $\mathrm{Co}-\mathrm{Gr} / \mathrm{SiO}_{2}(2)$.

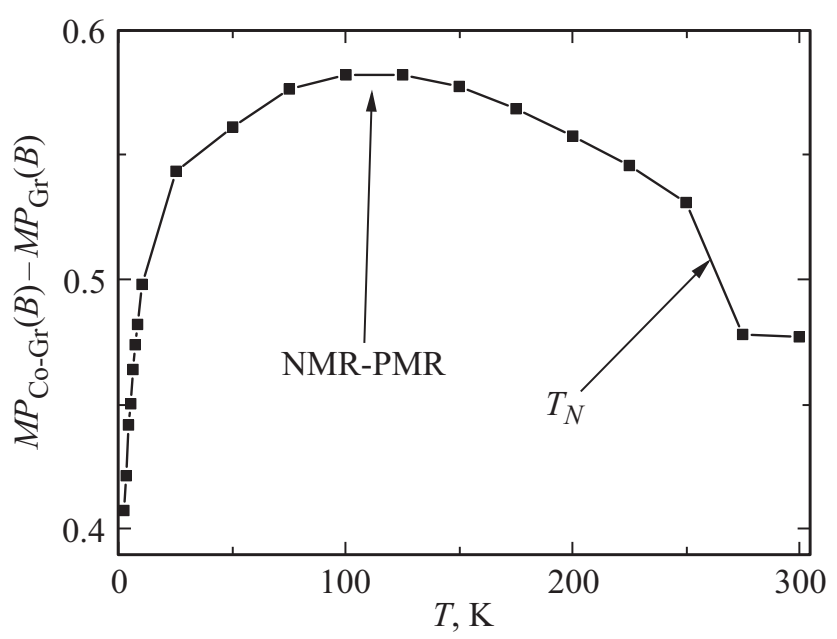

Рис. 11. Температурные зависимости разностей относительного магнитосопротивления образцов $\mathrm{Gr} / \mathrm{SiO}_{2}$ и $\mathrm{Co}-\mathrm{Gr} / \mathrm{SiO}_{2}$ $\left[M R_{\mathrm{Co}-G r}(T, 8 \mathrm{~T})-M R_{G r}(T, 8 \mathrm{~T})\right]$ в магнитном поле $B=8 \mathrm{~T}$ с указанием критических температур переходов ОМР-ПМР и точки Нееля $T_{\mathrm{N}}$ для $\mathrm{CoO}$.

член) $[35,39,40]$. Таким образом, соотношения (2) и (3) дают возможность оценить характерные времена сбоя фазы для разных вкладов на основе соответствующей процедуры фиттинга. Результаты проведенного фиттинга для диапазона слабых магнитных полей $(B<1$ T, т.е. в области существования ОМР) на рис. 10, подтверждают степенной ход температурной зависимости времени сбоя фазы (4), давая значения параметра $p$ равные 1.07 и 0.71 для исходного графена (прямая 1) и графена с осаждеными частицами кобальта (прямая 2) соответственно. Таким образом, температурный ход $R_{\square}(T)$ и магнетополевые зависимости $M P(B)$ указывают на ведущую роль квантовых поправок в низкотемпературном электропереносе изученных образцов как до, так и после его декорирования частицами кобальта. Как показал фиттинг, остальные члены в соотношении (2) в полях ниже 1 Т и при температурах менее $75 \mathrm{~K}$ дали вклады, не превышающие $0.1 \%$ от слаболокализационного. Их роль в низкотемпературном электротранспорте, возможно, проявляется в области ПМР, т.е. в более сильных магнитных полях.

Таким образом, можно констатировать, что декорирование частицами кобальта существенно изменяет как температурные, так и магнитополевые зависимости намагниченности и слоевого электросопротивления образцов, однако по-разному в различных областях температуры и магнитного поля. На рис. 11 представлена температурная зависимость разности относительного магниторезистивного эффекта $\left[M R_{\mathrm{Co}-G r}(T, 8 \mathrm{~T})-M R_{G r}(T, 8 \mathrm{~T})\right]$ для образцов $G r / \mathrm{SiO}_{2}$ и $\mathrm{Co}-G r / \mathrm{SiO}_{2}$ в магнитном поле $B=8 \mathrm{~T}$, что позволяет выделить вклад частиц кобальта в магнетотранспорт. Видно, что кривая проходит через максимум в области температур порядка $100 \mathrm{~K}$, положение которого соответствует окончанию температурной области существования ОМР в образце $\mathrm{Co}-G r / \mathrm{SiO}_{2}$. При росте температуры выше 250-275 K наблюдается резкий спад кривой, совпадающий с аналогичным спадом слоевого сопротивления $R_{\square}(T)$ на кривых 2 на рис. 4, что ранее нами было связано с переходом антиферромагнитного $\mathrm{CoO}$ в парамагнитное состояние выше температуры Нееля.

Отметим, что снижение величины $\left[M R_{\mathrm{Co}-G r}(T, 8 \mathrm{~T})\right.$ $\left.-M R_{G r}(T, 8 \mathrm{~T})\right]$ с ростом температуры выше $100 \mathrm{~K}$ может служить еще одним подтверждением роли механизма Лоренца в увеличении ПМР за счет влияния ядра кобальта, хотя нет оснований полностью исключать влияния положительных квантовых поправок в ПМР [28].

\section{4. Заключение}

В работе показано, что электрохимическое осаждение из электролита кобальтирования в реверсивном режиме приводит к формированию на CVD-графене частиц $\mathrm{Co}-\mathrm{CoO}$ в виде агломераций (размером до $500 \mathrm{~nm}$ ), состоящих из частиц вытянутой формы с полидисперсным распределением по размерам. Поверхностное окисление частиц кобальта проявляется в наблюдаемой асимметрии кривых намагниченности $M(H)$ и резком спаде температурных кривых слоевого электросопротивления $R_{\square}(T)$ для образца $\mathrm{Co}-G r / \mathrm{SiO}_{2}$ ниже температуры Нееля.

Показано, что осаждение частиц Со-СоО приводит к повышению сопротивления графена вследствие уменьшения концентрации электронов. В образцах $\mathrm{Gr} / \mathrm{SiO}_{2}$ и $\mathrm{Co}-\mathrm{Gr} / \mathrm{SiO}_{2}$ обнаружена конкуренция отрицательного (ОМР) и положительного (ПМР) вклада в магниторезистивный эффект, и показано, что низкотемпературный электроперенос в области ОМР обусловлен локализационной квантовой поправкой к проводимости Друде, 
а усиление ПМР после осаждения на графене частиц $\mathrm{Co}-\mathrm{CoO}$, может быть обусловлено влиянием лоренцевого механизма внутри зерен Сo.

\section{Финансирование работы}

Работа финансировалась Государственным комитетом по науке и технологиям Республики Беларусь (договор Ф18ПЛШГ-005), государственными программами научных исследований „Фотоника, опто- и микроэлектроника“ (задание 3.3.01) и в рамках контракта № 08626319/182161170-74 с Объединенным институтом ядерных исследований (Россия), а также за счет гранта Российского научного фонда (проект № 19-79-30062) в части синтеза и переноса графена на подложки.

\section{Конфликт интересов}

Авторы заявляют, что у них нет конфликта интересов.

\section{Список литературы}

[1] I.S. Zhidkov, N.A. Skorikov, A.V. Korolev, A.I. Kukharenko, E.Z. Kurmaev, V.E. Fedorov, S.O. Cholakh. Carbon 91, 298 (2015).

[2] P.U. Asshoff, J.L. Sambricio, A.P. Rooney, S. Slizovskiy, A. Mishchenko, A.M. Rakowski, E.W. Hill, A.K. Geim, S.J Haigh, V.I. Fal'ko, I.J. Vera-Marun, I.V. Grigorieva. 2DMater. 4, 031004 (2017).

[3] M.Z. Iqbal, M.W. Iqbal, J.H. Lee, Y.S. Kim, S. Chun, J. Eom. NanoResearch 6, 5, 373 (2013).

[4] V.C. De Franco, G.M.B. Castro, J. Corredor, D. Mendes, J.E. Schmidt. Carbon Lett. 21, 16 (2017).

[5] V.G. Bayev, J.A. Fedotova, J.V. Kasiuk, S.A. Vorobyova, A.A. Sohor, I.V. Komissarov, N.G. Kovalchuk, S.L. Prischepa, N.I. Kargin, M. Andrulevičius, J. Przewoznik, Cz. Kapusta, O.A. Ivashkevich, S.I. Tyutyunnikov, N.N. Kolobylina, P.V. Guryeva. Appl. Surf. Sci. 440, 1252 (2018).

[6] B.L. Altshuler, A.G. Aronov, D.E. Khmelnitsky. J. Phys. C 15, 7367 (1982).

[7] J. Jobst, D. Waldmann, I.V. Gornyi, A.D. Mirlin, H.B. Weber. Phys. Rev. Lett. 108, 106601 (2012).

[8] S.V. Morozov, K.S. Novoselov, M.I. Katsnelson, F. Schedin, L.A. Ponomarenko, D. Jiang, A.K. Geim. Phys. Rev. Lett. 97, 016801 (2006).

[9] B.I. Shklovskii, A.L. Efros. Electronic properties of doped semiconductors. Heidelberg, Springer Series in Solid-State Sciences (1984).

[10] B.I. Shklovskii. Semiconductors 6, 1964 (1973).

[11] N. Mikoshiba. J. Phys. Chem. Solids 24, 341 (1963).

[12] S.A. Solin, L.R. Ram-Mohan. Geometry-Driven Magnetoresistance, in Handbook of Magnetism and Advanced Magnetic Materials. American Cancer Society (2007). P. 19.

[13] H.M. So, J.H. Mun, G.S. Bang, T.Y. Kim, B.J. Cho, C.W. Ahn. Carbon Lett. 13, 56 (2012).

[14] A.C. Ferrari, J.C. Meyer, V. Scardaci, C. Casiraghi, M. Lazzeri, F. Mauri, S. Piscanec, D. Jiang, K.S. Novoselov, S. Roth, A.K. Geim. Phys. Rev. Lett. 97, 187401 (2006).
[15] V.T. Nguyen, H.D. Le, V.C. Nguyen, T.T.T. Ngo, D.Q. Le, X.N. Nguyen, N.M. Phan. Adv. Nature. Sci.: Nanosci. Nanotechnol. 4, 035012 (2013).

[16] X. Dong, P. Wang, W. Fang, C.-Y. Su, Y.-H. Chen, L.-J. Li, W. Huang, P. Chen. Carbon 49, 3672 (2011).

[17] I. Shlimak, A. Haran, E. Zion, T. Havdala, Yu. Kaganovskii, A.V. Butenko, L. Wolfson, V. Richter, D. Naveh, A. Sharoni, E. Kogan, M. Kaveh. Phys. Rev. B 91, 045414 (2015).

[18] H. Wang, Y. Wang, X. Cao, M. Feng, G. Lan. J. Raman Spectrosc. 40, 1791 (2009).

[19] R. Saito, M. Hofmann, G. Dresselhaus, A. Jorio, M.S. Dresselhaus. Adv. Phys. 60, 413 (2011).

[20] R.D. Gomez, M.C. Shih, R.M.H. New, R.F.W. Pease, R.L. White. J. Appl. Phys. 80, 342 (1996).

[21] R.M.H. New, J. Vac. Sci. Technol. B Microelectron. Nanom. Struct. 13, 1089 (1995).

[22] P. Ares, M. Jaafar, A. Gil, J. Gõmez-Herrero, A. Asenjo. Small 11, 4731 (2015).

[23] J. Nogues, J. Sort, V. Langlais, V. Skumryev, S. Suriñach, J.S. Muñoz, M.D. Baró. Phys. Rep. 422, 65 (2005).

[24] R. López Antón, J.A. González, J.P. Andrés, J. CanalesVázquez, J.A. De Toro, J.M. Riveiro. Nanotechnology 25, 105702 (2014).

[25] S. Sako, K. Ohshima, M. Sakai, S. Bandow. Surf. Rev. Lett. 3, 109 (1996).

[26] K. Takehana, Y. Imanaka, E. Watanabe, H. Oosato, D. Tsuya, Y. Kim, Ki-Seok An. Current Appl. Phys. 17, 474 (2017).

[27] V.M. Pudalov. In Proceedings of the International School of Physics „Enrico Fermi“ 157, 335 (2004).

[28] E. Zion, A. Haran, A. Butenko, L. Wolfson, Y. Kaganovskii, T. Havdala, A. Sharoni, D. Naveh, V. Richter, M. Kaveh, E. Kogan, I. Shlimak. Graphene 4, 45 (2015).

[29] Т.А. Полянская, Ю.В. Шмарцев. ФТП 23, 3 (1989).

[30] V.K. Tewary, B. Yang. Phys. Rev. B 79, 125416 (2009).

[31] F.V. Tikhonenko, D.W. Horsell, R.V. Gorbachev, A.K. Savchenko. Phys. Rev. Lett. 100, 056802 (2008).

[32] N.F. Mott, E.A. Davis. Electronic processes in non-crystalline materials. 2nd ed. Oxford University Press (1979). 580.

[33] R.V. Gorbachev, F.V. Tikhonenko, A.S. Mayorov, D.W. Horsell, A. Savchenko. Phys. Rev. Lett. 98, 176805 (2007).

[34] K. Kechedzhi, E. Mccann, V.I. Fal'ko, H. Suzuura, T. Ando, B.L. Altshuler. Eur. Phys. J. Spec. Top. 148, 39 (2007).

[35] E. McCann, K. Kechedzhi, V.I. Fal'ko, H. Suzuura, T. Ando, B.L. Altshuler. Phys. Rev. Lett. 97, 146805 (2006).

[36] B.L. Altshuler, A.G. Aronov. Mod. Probl. Condens. Matter Sci. 10, 1 (1985).

[37] R. Oppermann, M.J. Schmidt, D. Sherrington. Phys. Rev. Lett. 98, 127201 (2007).

[38] A.V. Germanenko, G.M. Minkov, O.E. Rut. Phys. Rev. B 64, 165404 (2001).

[39] C.W.J. Beenakker, H.V. Houten. Solid State Phys. 44, 1 (1991).

[40] B.L. Altshuler, D. Khmel'nitzkii, A.I. Larkin, P.A. Lee. Phys. Rev. B 22, 5142 (1980).

Редактор Т.Н. Василевская 